DENTAL NURSE RETURNS TO PRACTICE AS DENTIST

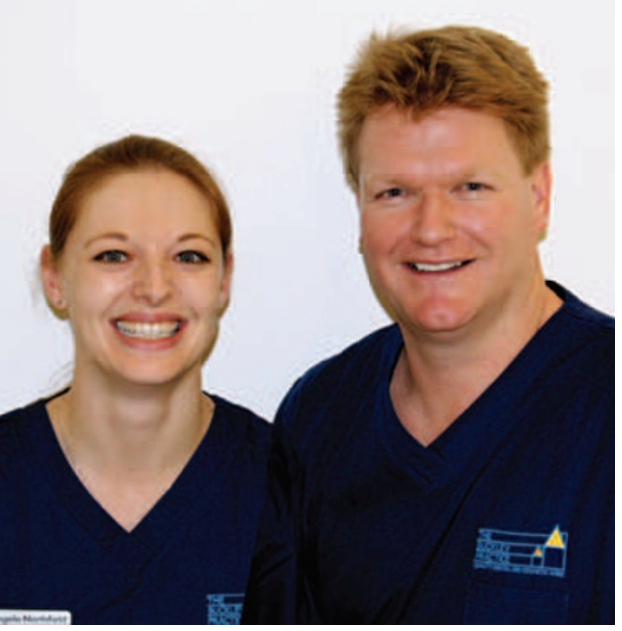

A dental nurse in Bromley has returned to the practice she originally joined 14 years earlier as a fully qualified dentist.

Dr Angela Northfield is the new associate dentist at the Buckley Practice in Bromley where she once assisted principal Dr Seán Buckley as dental nurse.

Dr Northfield began her career as a dental nurse at the Buckley Practice but six years on went to Guy's Hospital to study dentistry after studying extensively at night.

Dr Northfield remarked: 'I feel I'm going back to my dental roots and I really feel like I'm returning home. I'm looking forward to seeing some of the established patients again and meeting some new ones too.'

Dr Buckley commended his new associate's extraordinary achievement: 'To the best of my knowledge [this] is unprecedented. We are so proud of Angela.'

\section{ACUPUNCTURE RELIEVES DRY MOUTH}

A study conducted at seven cancer centres in the UK has shown that acupuncture can relieve the symptoms of xerostomia. ${ }^{1}$

Doctors recruited 145 patients suffering from radiation-induced xerostomia to a trial comparing acupuncture with education about oral care. Although the researchers found that there were no significant changes in saliva production, patients who had received nine weeks of acupuncture (for 20 minutes every week for eight weeks) were twice as likely to report improved dry mouth than patients receiving oral care. Individual symptoms were also significantly improved among the group receiving acupuncture.

Dr Richard Simcock, consultant clinical oncologist at the Sussex Cancer Centre and one of the authors of the study, said: 'Time had an important effect on key symptoms, with patients receiving acupuncture showing a quick response, which was sustained over several weeks.'

The researchers said that further studies are needed to refine the acupuncture technique and discover how long its effect lasts and whether booster sessions might be required, but they believe it could be easily incorporated into the care of patients with xerostomia.

1. Simcock $\mathrm{R}$, Fallowfield $\mathrm{L}$, Monson $\mathrm{K}$ et al. ARIX: A randomised trial of acupuncture $\checkmark$ oral care sessions in patients with chronic xerostomia following treatment of head and neck cancer. Ann Oncol 2012; [Epub ahead of print].

\title{
CLINICAL ACADEMICS' CONTRIBUTIONS RECOGNISED
}

The Dental Schools Council greatly welcomes the proposals from the UK Departments of Health in response to the report from the Review Body on Doctors' and Dentists' Remuneration (DDRB), and holds the suggested changes to be an effective way of recognising the contributions of clinical academics.

Local Clinical Excellence Awards are to be replaced with funds allocated to Trusts and distributed annually as they see fit. It will be important to ensure that Trusts recognise the contribution of academics with honorary contracts as well as their full time staff. National Clinical Excellence Awards are to remain as an important platform for recognising those individuals engaged in world-leading research.

Clinical academics are uniquely placed in being able to use their practical experience to inform their research, ensuring the dental advancements they are engaged in to be always relevant to the changing needs of patients. They form a 'key point of contact between the various scientific disciplines and how they relate to dentistry, fostering a unique level of innovation, all in an atmosphere of creativity and cooperation'. As teachers clinical academics are responsible for training the next generation of dentists. Effective awards schemes such as that proposed by the DDRB are part of ensuring those hands are among the most skilled and experienced in the world.

\section{PERIODONTITIS LINKED} TO PSORIASIS

A new study from Taiwan links the presence of severe gum disease with the skin condition psoriasis. ${ }^{1}$

In a group of 230,000 people, researchers found that those with severe gum disease were 54\% more likely to develop psoriasis over five years. Psoriasis affects around 1.8 million people in the UK.

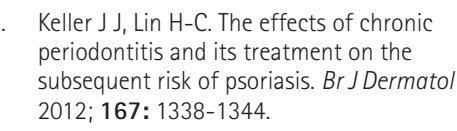

\section{YOU OTTER}

\section{SEE A DENTIST}

A dual-qualified vet and human dentist called Dr Anthony Caiafa has performed a tooth extraction on an otter for the first time, as reported in the Sunshine Coast Daily. Dr Caiafa is one of the few people in Australia to be qualified to treat both animals and people.

Kaos, an Asian small clawed otter and eight-year resident of UnderWater World in Mooloolaba, two hours north of Brisbane, underwent surgery to remove one of his lower molars. Dr Caiafa practises human dentistry, is the referral dentist for a veterinary practice and teaches vet studies at a university.

'I've performed many tooth extractions and root canals on many different animals, but not an otter, said Dr Caiafa. 'The procedure for Kaos is the same as a tooth extraction for a human - certainly a little easier than my last patient: a crocodile with a fractured jaw in Victoria.' 